\title{
NO VIOLENCIAS CONTRA LA MUJER. DERECHO HUMANO DE CARÁCTER ABSOLUTO ${ }^{1}$
}

No Violence against Women. Human Rights of Absolute Character

\author{
Zulay María Rodríguez Bermúdez ${ }^{2}$
}

Fecha de Recepción: 18 de mayo de 2016

Fecha de Aceptación: 20 de mayo de 2016

SUMARIO: 1. Introducción; 2. Objeto de la ley para una vida como mujer libre de violencias, ley 1257 de 2008; 3. Definición y tipo de violencia; 4. Clases de daños generados a la mujer víctima de los distintos tipos de violencia; 5 . Prejuicios y mitos sobre la violencia contra las mujeres; 6. ¿Por qué la mujer violentada tolera la violencia y no abandona al victimario? El ciclo de la violencia; 7.Corresponsabilidad entre familia, sociedad y estado, para prevenir la violencia contra la mujer; 8. Conclusiones; 9. Referencias Bibliográficas.

\footnotetext{
${ }^{1}$ El presente artículo es elaborado como resultado de las actividades de investigación y de reflexión, del Semillero de Investigación de la Facultad de Derecho de la Universidad Libre, Sede Cartagena, liderado por la autora.

${ }^{2}$ Abogada, especialista en Derecho Público de la Universidad Externado de Colombia. Magister en Derecho de la Universidad de Medellín. Docente de la Universidad de Cartagena, de la Universidad Libre Sede Cartagena y de la Universidad San Buenaventura, Sede Cartagena. Miembro del Grupo de Investigación “Conflicto y Sociedad” de la Universidad de Cartagena. Correo: zulay-maria@hotmail.com
} 


\section{CÓMO SE CITA ESTE ARTíCULO (Normas APA-6)}

Rodríguez Bermúdez, Zulay María (2016). No violencias contra la mujer. Derecho humano de carácter absoluto. Revista Jurídica Mario Alario D’Filippo, VIII (16), pág 159-174.

\section{RESUMEN}

El presente artículo propone una reflexión en cuanto al tema de la violencia contra la mujer, basada en el género, fenómeno social que ha recibido categoría de problema de salud pública. Su contenido está basado en estudios sobre la tolerancia a la violencia contra la mujer, los mitos que la perpetúan, las clases de violencia de la que ella puede ser víctima, solo por el hecho de ser mujer, y los diferentes daños que a una mujer se ocasionan como consecuencia de las distintas clases de violencia que se le pueden infligir. También propone una reflexión sobre las causas que le impiden a una mujer violentada poner distancias físicas y emocionales con el victimario y las obligaciones de la familia, la sociedad y el Estado (a través de las distintas autoridades administrativas involucradas en la prevención y atención de estos casos), a la luz de la Ley 1257 de 2008, como corresponsables de la prevención de tal tipo de violencia y de la restauración integral de una mujer víctima de agresión.

\section{PALABRAS CLAVE}

Mujer, violencia basada en el género, familia, daño, autoridades administrativas.

\section{ABSTRACT}

This paper proposes a reflection on the theme of violence against women, based on gender, a social phenomenon that has received a category of public health problem. Its content is based on studies on tolerance to violence against women, the myths that perpetuate it, the kinds of violence she can be victim of, just because it is a woman, and the different damages that a woman, caused by the different kinds of violence that can be inflicted. It also proposes a reflection on the causes that prevent a violent woman from putting physical and emotional distances with the victimizer and the obligations of the family, society and the State (through the various administrative authorities involved in the prevention and care of these cases), in light of Law 1257 of 2008, as co-responsible for the prevention of such type of violence and the integral restoration of a woman victim of aggression.

\section{KEYWORDS}

Woman, gender-based violence, family, damage, administrative authorities. 


\section{INTRODUCCIÓN}

A pesar del concepto judeo-cristiano de creación de la mujer como un ser igual al hombre que, con distintos matices ha sido siempre empleado por la mayoría de las religiones para describir el origen de ambos sexos, la mujer, de manera reiterada, en las diferentes épocas de la humanidad, ha sido considerada "menos importante" que el hombre. Más allá de las reivindicaciones de derechos políticos y económicos logradas en el pasado Siglo $X X$, aún subsiste la problemática de la violencia contra la mujer, sólo por el hecho de ser mujer, que ha venido ser considerada como violencia basada en género. Esta especie de violencia se encuentra justificada en la sumisión al hombre que se cree que debe cumplir la mujer cualquiera que sea su condición: hija, cónyuge, compañera permanente, novia, hermana y hasta madre o abuela.

La violencia contra la mujer, basada en el género, ha sido considerada como un problema de salud pública que importa a todos los Estados. El compromiso para su disminución fue contemplado como el Tercero de los Objetivos del Milenio, consistente en "promover la igualdad entre los géneros y la autonomía de la mujer". Los esfuerzos de Colombia, sin embargo, según datos publicados en la página virtual del Programa de las Naciones Unidas en Colombia:

no han sido suficientes y muchos de ellos han resultado ineficaces, por lo cual se siguen vulnerando de manera ostensible los derechos humanos de las mujeres. Así lo indica el hecho de que en 2005 el 39\% de las mujeres había experimentado violencia física por parte de su esposo o compañero y en 2010 lo habían experimentado el 37,40\%, es decir, una reducción apenas de 2,4\% en cinco años; peor aún, en 2005 el 65,7\% habían experimentado violencia psicológica, y en 2010 ese tipo de violencia se elevó considerablemente a 72,50.

A continuación definiremos qué es la violencia contra la mujer y sus modalidades. Explicaremos también por qué se perpetúa y cómo debe colaborar la familia y la sociedad con el Estado, para prevención y su disminución. Para ello, inicialmente estudiaremos algunos de los mitos y prejuicios que, de no ser transformados, perpetúan o justifican equivocadamente la violencia contra la mujer, sólo por el hecho de ser mujer. Seguidamente trataremos los tipos de violencia contra ella, y luego pasaremos a examinar las indicaciones de la Ley 1257 de 2008, expedida por el Congreso de la República de Colombia, todo ello con el interés de colaborar en la visualización e implementación de la prevención del problema. Aclaramos que no será posible tratar aquí la violencia basada en género contra la mujer en conflicto armado, por las particularidades de ese tipo de violencia y el límite de amplitud de este artículo.

Además de la motivación social, basada en la inquietud por el incremento de casos, tenemos la preocupación académica. A pesar de la expedición de la Ley 1257 de 2008, y de sus subsiguientes decretos reglamentarios para regular su desarrollo en cuanto a salud, educación y trabajo, en los diferentes cursos universitarios a los que he tenido 
el honor de atender, entre los que se encuentran carreras profesionales tales como Medicina, Derecho y Administración de Empresas, con estudiantes llamados a ser parte de la solución desde su intervención como médicos, defensores de las víctimas y hasta empleadores de ellas, nos encontramos no sólo con la ignorancia sobre el tema, sino con la mirada desapercibida de ellos, producto del desconocimiento de tal tipo de violencia como lo que es: una violencia que, para ser superada, requiere un tratamiento diferencial.

Por ello este constituye uno de los primeros artículos de reflexión sobre la violencia contra la mujer, solo por el hecho de ser mujer, dirigidos a la ciudadanía en general, que seguramente servirá de multiplicador de un conocimiento que procura la mejora de condiciones de vida de nuestras mujeres colombianas. Más adelante se hará necesario reflexionar sobre cada tipo de violencia y sobre los ámbitos en los que se presenta, distinto al familiar, tales como el laboral y social, así como también será propicio una reflexión sobre el recién reconocido hecho punible llamado "feminicidio".

Como el tema no es ligero ni intrascendente, la Corte Constitucional ha debido involucrarse con regular frecuencia. De sus pronunciamientos citamos las siguientes sentencias que pueden ser de utilidad para los lectores: C-776 de 2010, mediante la cual, entre otros aspectos, se declaró la exequibilidad de la prestación de los servicios de hotelería y comida para la víctima de agresión sexual y sus familiares, en el entendido de que estos guardan relación con la recuperación de la salud; C-335 de 2013, mediante la cual se declaró la exequibilidad de la sanción social que puede serle impuesta al agresor; T-967 de 2014, mediante la cual, la Corte reconoció como causal de divorcio los malos tratos originados en los celos del cónyuge y T-878 de 2014, mediante la cual se ordenó a un empleador, persona jurídica de derecho privado, el reintegro de una mujer violentada a su trabajo para protegerle su estabilidad económica como respaldo para su recuperación de la violencia de género de la que había sido víctima.

\section{OBJETO DE LA LEY PARA UNA VIDA COMO MUJER LIBRE DE VIOLENCIAS, LEY 1257 DE 2008}

Nuestro estado colombiano, en los últimos años, ha reconocido la existencia en la población de ciertos grupos históricamente discriminados, dentro de los cuales se encuentran las mujeres, y por ello, busca que mediante acciones afirmativas, o de discriminación positiva, se logre la finalidad de alcanzar una igualdad real entre hombres y mujeres.

La Declaración sobre la eliminación de la violencia contra la mujer, proclamada por la Asamblea General de las Naciones Unidas en su Resolución 48/104, de 20 de diciembre de 1993, establece en el literal j de su artículo 4, la obligación para todos los miembros de dicha organización de 
Adoptar todas las medidas apropiadas, especialmente en el sector de la educación, para modificar las pautas sociales y culturales de comportamiento del hombre y de la mujer y eliminar los prejuicios y las prácticas consuetudinarias o de otra índole basadas en la idea de la inferioridad o la superioridad de uno de los sexos y en la atribución de papeles estereotipados al hombre y a la mujer.

Esa es una de las razones de la expedición de la Ley 1257 de 2008, mediante la cual "se dictan normas de sensibilización, prevención y sanción de formas de violencia y discriminación contra las mujeres, se reforman los Códigos Penal, de Procedimiento Penal, la Ley 294 de 1996 y se dictan otras disposiciones". El principal propósito de esta ley es la búsqueda del establecimiento de relaciones pacíficas, solidarias, respetuosas e igualitarias con las mujeres y la prevención y disminución de las agresiones contra ellas, por el hecho de ser mujeres, sin tener en cuenta condiciones de edad, sociales o de elecciones sexuales. La norma declara de manera categórica que

Las mujeres tienen derecho a una vida digna, a la integridad física, sexual y psicológica, a la intimidad, a no ser sometidas a tortura o a tratos crueles y degradantes, a la igualdad real y efectiva, a no ser sometidas a forma alguna de discriminación, a la libertad y autonomía, al libre desarrollo de la personalidad, a la salud, a la salud sexual y reproductiva y a la seguridad personal.

Así pues, el objeto de la ley es bastante claro. Ella misma expresa que busca:

normas que permitan garantizar para todas las mujeres una vida libre de violencia, tanto en el ámbito público como en el privado, el ejercicio de los derechos reconocidos en el ordenamiento jurídico interno e internacional, el acceso a los procedimientos administrativos y judiciales para su protección y atención, y la adopción de las políticas públicas necesarias para su realización.

Este objeto destaca la intención de una vida libre de violencias en el ámbito privado ya que, históricamente, la violencia intrafamiliar se había visto como algo de la "esfera privada" de las mujeres, o de la pareja, o como coloquialmente se solía decir "en pelea de marido y mujer, nadie se puede meter". Es necesario clarificar que el amparo a la mujer se extiende a evitar que personas diferentes a sus parejas le agredan, como sucede respecto de lasierr previsión sobre la violencia económica, La Ley advierte que además de presentarse en el ámbito de pareja, también puede presentarse en el ámbito laboral o de relaciones económicas, como por ejemplo, entendemos nosotros, en relaciones mercantiles o de contratos.

\section{DEFINICIÓN Y TIPOS DE VIOLENCIA}

Tradicionalmente la violencia contra la mujer sólo había sido entendida como la violencia física, ocasionada en su cuerpo, que pudiere causarle lesiones o la muerte. Más recientemente se había comprendido que también consistía en la agresión o coacción 
sicológica, pero la Ley 1257 de 2008 precisa que además de la muerte, el daño o el sufrimiento físico o sicológico también constituye violencia contra ella la acción u omisión que deriva en daño sexual, económico o patrimonial, por su condición de mujer, así como las amenazas de tales actos, la coacción o la privación arbitraria de la libertad.

Especial atención también debemos brindar al tipo de violencia económica, la cual por décadas ha debido afrontar la mujer, desde que alcanzó reconocimiento por su producción, y que consiste en el abuso económico o el control abusivo de las finanzas de la mujer, o el ofrecerle recompensas o castigos monetarios, por razón de su condición social, económica o política. Esta forma de violencia puede consolidarse en las relaciones de pareja y familiares, así como en las laborales o en las económicas, tales como el ejercicio de actos de comercio por parte de la mujer.

\section{CLASES DE DAÑOS GENERADOS A LA MUJER VÍCTIMA DE LOS DISTINTOS TIPOS DE VIOLENCIA}

De la ocurrencia de los tipos de violencia que detallamos en el aparte anterior se derivan daños concretos para la mujer, que la Ley 1257 de 2008, se ha esforzado en discriminar así:

a) Daño psicológico: es el que se presenta cuando mediante acciones u omisiones se pretende degradar o controlar las acciones, comportamientos, creencias y decisiones de la mujer, ya sea intimidándola, manipulándola, amenazándola, directa o indirectamente, humillándola, aislándola o mediante cualquier otro actuar u omitir que implique un perjuicio en su salud psicológica, su autodeterminación o desarrollo personal.

b) Daño o sufrimiento físico: Riesgo o disminución de la integridad corporal de una mujer.

c) Daño o sufrimiento sexual: se presenta porque, mediante el uso de fuerza, intimidación, coerción, chantaje, soborno, manipulación, amenaza o cualquier otro mecanismo se anule o limite la voluntad personal, para obligar a una persona a mantener contacto sexualizado, físico o verbal, o a participar en otras interacciones sexuales, o a realizar alguno de estos actos con terceras personas.

d) Daño patrimonial: Pérdida, transformación, sustracción, destrucción, retención o distracción de objetos, instrumentos de trabajo, documentos personales, bienes, valores, derechos o económicos destinados a satisfacer las necesidades de la mujer ${ }^{3}$

\section{PREJUICIOS Y MITOS SOBRE LA VIOLENCIA CONTRA LAS MUJERES}

Por tradición, en casi todas las etapas del desarrollo de la humanidad y en casi todas las culturas, han existido algunos prejuicios y mitos, carentes de fundamento, que han permitido perpetuar la violencia contra la mujer. A continuación detallamos los más comunes $^{4}$ :

\footnotetext{
${ }^{3}$ Véase el contenido completo de la Ley recuperado de http://www.alcaldiabogota.gov.co/sisjur/normas/Norma1.jsp?i=34054

${ }^{4}$ Los siguientes mitos los hemos adaptado de la entrada, en el portal CCM, Violencia sobre las mujeres: algunas ideas falsas. Recuperado de: http://salud.ccm.net/faq/6047-violencia-sobre-las-mujeres-algunas-ideas-falsas.
} 
1‥ La violencia contra la mujer es un problema privado. Es falso porque la violencia contra la mujer NO es un problema privado, pues atenta contra la libertad y seguridad de la víctima, lo cual es de interés para la sociedad y el Estado:

- Además está considerado como un delito y los delitos jamás son cuestiones privadas.

- Intentar reducir la violencia al ámbito privado impide que la sociedad se haga cargo del problema.

- En muchos casos está asociado con otros problemas sociales como el alcoholismo, las drogas, la delincuencia juvenil, el suicidio, etc., los cuales también son del interés de la sociedad y el Estado.

2‥ La violencia contra las mujeres es un problema únicamente de las clases sociales más bajas. Es falso (Naizara, 2008):

- La agresión afecta a todas las clases sociales y económicas.

- A menudo las mujeres de clase media-alta no recurren a los servicios sociales porque la presentación de una denuncia afectaría a su estatus social.

- Las mujeres con bajos recursos acuden más a los servicios sociales y les da menos reparos hablar de su situación, porque no tienen problemas de estatus social.

3‥ Un hombre no maltrata porque sí; "ella habrá hecho algo para provocarle". Es falso:

- Este mito es triste y está muy arraigado en la sociedad.

- Lo más grave es que esta creencia responsabiliza a la mujer del comportamiento violento del hombre y le impide a él asumir las consecuencias de su violencia.

- El maltratador basa su autoestima en su capacidad de controlar y dominar a la mujer y pretende su sumisión total.

- Cuando la sociedad hace eco del mito de la "provocación por ser mujer" impide que la propia víctima reconozca la violencia que padece y emprenda acciones para apartarse del maltratador.

4‥ Las mujeres maltratadas no se separan porque les gusta que les peguen. Es falso:

- Esta interpretación simplista responsabiliza otra vez a la mujer. Más adelante ampliaremos las razones que explican por qué la mujer violentada tiene dificultad para separarse del agresor.

5‥ Los maltratadores tienen problemas con el alcohol o drogas. No siempre:

- A menudo estos problemas van asociados, pero no todos los hombres que son alcohólicos pegan y maltratan a sus parejas.

- Las drogas o el alcohol, pueden agudizar comportamientos violentos, pero no los originan. ${ }^{5}$

${ }^{5}$ Ver también: Walker, L. (2012). El síndrome de la mujer maltratada. España: Editorial Desclée De Brouwer, p. 35. 
6‥ Los maltratadores son enfermos. Es falso:

- La violencia es el resultado de relaciones de poder entre hombres y mujeres y tratar a los violentos como enfermos, justifica su violencia ${ }^{6}$

- Es habitual que hombres que maltratan a sus parejas, no sean violentos con otras personas; es más, con frecuencia, son socialmente amables y respetuosos.

- Descargan su ira con su pareja porque se sienten con derecho sobre ella, siendo plenamente conscientes de sus actos.

70. Los niños no perciben la violencia en el hogar. Es falso.

- En los hogares de madres que son maltratadas los niños corren serios riesgos de padecer violencia también.

- Lo más importante para el desarrollo de un niño es criarse en un ambiente amoroso y libre de violencia.

- Generalmente son los niños los que piden a la madre que se separe porque la situación les resulta insoportable.

- El ser testigo de violencia es un riesgo para la salud mental del niño y, en el futuro, es muy posible que también él sea un maltratador con su pareja porque es lo que ha aprendido.

8․ No existe la violación entre esposos, entre compañeros permanentes o entre novios, porque existe la obligación de la mujer de satisfacer sexualmente a su pareja en el momento que él lo quiera. Es falso:

- Una mujer es violada cuando es obligada a mantener una relación sexual que no desea.

- Una quinta parte de las mujeres maltratadas son forzadas a mantener relaciones sexuales durante el episodio de violencia o inmediatamente después.

- El 60 \% de las mujeres maltratadas sufren abusos sexuales por sus parejas.

- Las relaciones afectivas y sexuales, se suponen entre personas iguales y libres, para disfrutar de la intimidad, por tanto, lejos de cualquier servilismo o esclavitud.

9‥ El embarazo detiene la violencia. Es falso:

- Con el embarazo aumenta la capacidad de control del hombre sobre la mujer, en base a la existencia de mayores limitaciones y dependencias.

- El maltratador lo sabe y opera en consecuencia.

- Generalmente hay un aumento de la violencia durante el embarazo y muchas veces el primer episodio de violencia física se produce durante esa etapa.

${ }^{6}$ Íbid. p. 34. 
A continuación complementamos con los siguientes mitos y prejuicios que hemos adaptado de la conferencia dictada por la doctora Gloria Bonder, en el "Diplomado para la calidad de la atención a la violencia contra la mujer basada en el género", en la Universidad de Cartagena, en agosto de 2010:

10․ El hogar es el lugar más seguro para las mujeres, jóvenes, niños y niñas. Es falso porque las estadísticas revelan que la mayoría de abusos ocurren al interior de los hogares y son cometidos por parientes, cuidadores o amigos cercanos. Según un informe realizado a partir de datos del Instituto Nacional de Medicina Legal, en noviembre de 2014, aproximadamente cada día en el país 39 niños o niñas son víctimas de abuso sexual, siendo el principal escenario del delito el hogar de la víctima, con un 40 por ciento de los casos. ${ }^{7}$

11‥ Los hombres no pueden controlar sus instintos sexuales. Es falso, pues los hombres están dotados de autocontrol o dominio propio. Al igual que ocurre con el comportamiento de violencia física, se pretende justificar la violencia sexual, en la falta de autocontrol masculino. ${ }^{8}$

12‥ El hombre es el que decide todos los asuntos porque él sabe lo que conviene. Es falso y al igual que con el mito anterior, perpetúa la dominación varonil, la sumisión y sujeción a circunstancias violadoras de la dignidad de la mujer. ${ }^{9}$

13‥ La violencia es un instinto incontrolable. Es falso:

Aunque la organización patriarcal de la sociedad facilita e incluso recompensa el abuso a la mujer, algunos hombres hacen alarde de su potencial violento mientras que otros no. La violencia no surge de la interacción de las parejas en la relación, ni tampoco de la provocación causada por los irritantes rasgos de personalidad de las mujeres maltratadas, sino de las respuestas conductuales aprendidas por el maltratador ${ }^{10}$

14‥ Un padre es incapaz de violar a su hija. Es falso e infortunadamente las estadísticas revelan datos dolorosos al respecto. ${ }^{11}$

15‥ Una mujer no puede ser violada si no lo desea. Es falso, pues distintas condiciones, como las diferencias fisiológicas, en cuanto a la fuerza física, o condiciones mentales o emocionales, pueden colocar a una mujer en incapacidad para defenderse.

\footnotetext{
${ }^{7}$ Véase El Tiempo, edición virtual, recuperado de: http://www.eltiempo.com/politica/justicia/informe-sobre-abuso-sexual-infantilen-colombia/14850195

${ }^{8}$ Walker, L., op. cit.p.34.

${ }^{9}$ Ver también: Sierra, Z. Otra herencia colonial, el carácter androcéntrico y sexista del conocimiento. Mujer, Revista Javeriana, 2007 (p.60-69).

${ }^{10}$ Walker, L., op. cit.p.51.

11 Véase El Tiempo, edición virtual, http://www.eltiempo.com/politica/justicia/informe-sobre-abuso-sexual-infantil-encolombia/14850195.
} 
16‥ Los hombres son infieles por naturaleza. Es falso: ser fiel a su pareja o no serlo es una determinación tanto de hombres como de mujeres.

17‥ La mayoría de las violaciones las realizan desconocidos en lugares apartados y peligrosos. Es falso: lugares públicos como escuelas, parques y espacios de trabajo han sido escenarios de abusos sexuales. También se recuerda que el hogar ha venido a ser un lugar de peligro para sus integrantes femeninos. ${ }^{12}$

Los anteriores mitos y prejuicios, nos permiten entender, como lo expresa Ruiz (s.f) "que la violencia que se ejerce contra la mujer ha sido y es invisible e incluso está normalizada y naturalizada por la propia cultura" pero que "si deseamos mantener una sociedad en la que sea posible la convivencia y la resolución de conflictos de modo pacífico tendremos que promover todo tipo de acciones preventivas que vayan dirigidas a la eliminación de los estereotipos y roles de género" (10)

\title{
6. ¿POR QUÉ LA MUJER VIOLENTADA TOLERA LA VIOLENCIA Y NO ABANDONA AL VICTIMARIO? EL CICLO DE LA VIOLENCIA
}

La anterior es una pregunta que con frecuencia se suele hacer. Al respecto, Walker (2010) señala que:

\begin{abstract}
Algunos acontecimientos presentados en el pasado de las mujeres maltratadas, ocurrieron con suficiente regularidad [...] señalan un posible factor de susceptibilidad que interfiere en su capacidad para poner fin a la violencia del maltratador en el momento en que empieza a ejercerla. Originalmente se pensó que dicho potencial de susceptibilidad procedía de los rígidos patrones de socialización del rol sexual que hace que las mujeres adultas generen un sentido de impotencia aprendida que les impide desarrollar unas destrezas apropiadas para evitar ser maltratadas nuevamente. Esa teoría -refiriéndose a la "impotencia aprendida" por acontecimientos presentados en el pasado de una mujer maltratada- no contradice las importantes destrezas defensivas que desarrollan las mujeres maltratadas y que les protegen de ser lesionadas más gravemente o incluso de morir asesinadas. Sin embargo, eso demuestra el patrón psicológico que produce el impacto del abuso y nos ayuda a entender cómo algunas situaciones escalan sin intervención alguna (p. 40-41).
\end{abstract}

Lo anterior nos permite comprender entonces por qué una mujer que reiteradamente ha sido abusada por su pareja se encuentra en incapacidad para sustraerse a esa relación y tolera el abuso en medio de lo que se ha llamado el ciclo de la violencia. Éste suele estar conformado por las siguientes etapas que se suceden de manera circular. Veámoslo en el siguiente cuadro que debe ser leído en el sentido de las manecillas del reloj.

Como se observa, y siguiendo a Walker (2010), en una relación de maltrato, las etapas que se han identificado inician en un momento de acumulación de tensión, en la que

\footnotetext{
${ }^{12}$ |bídem.
} 


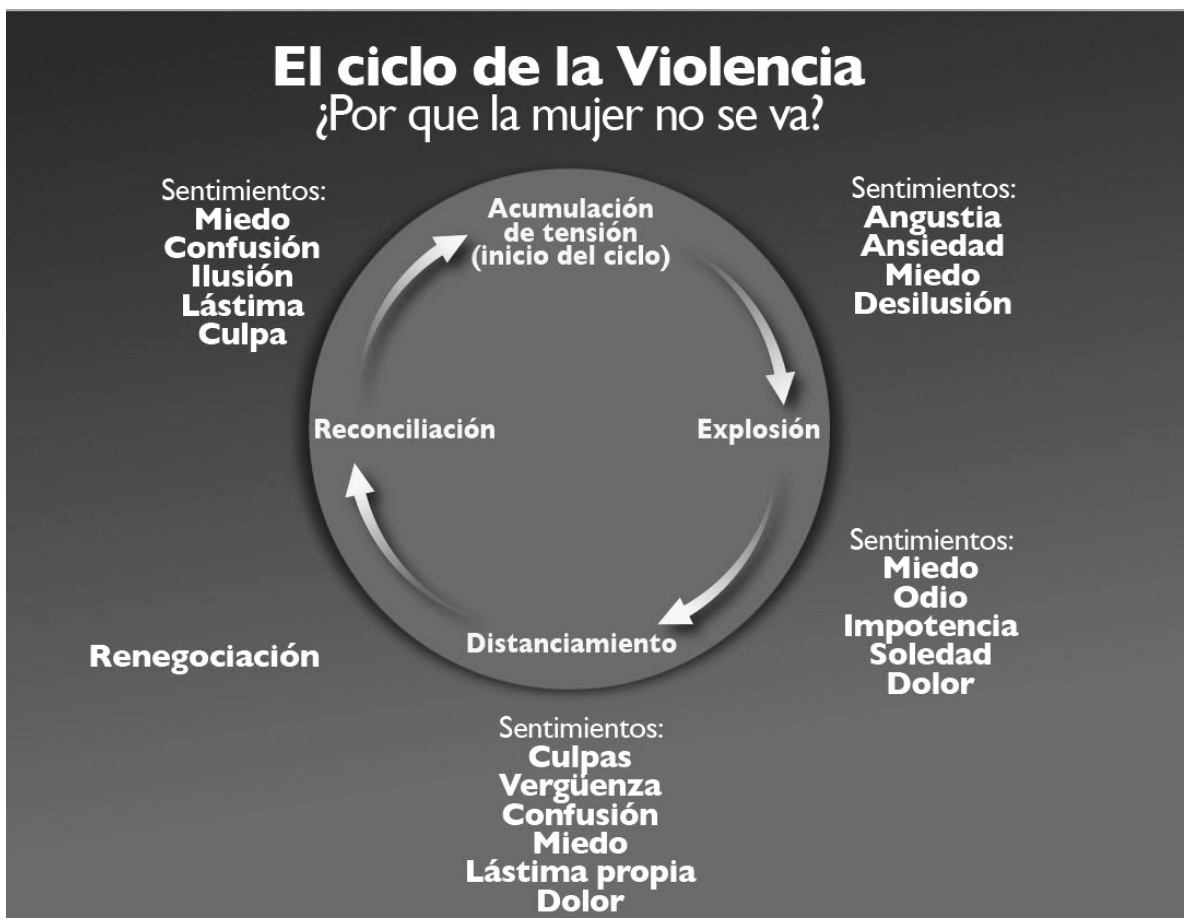

Gráfica suministrada por la doctora Gloria Bonder en el "Diplomado para la calidad de la atención a la violencia contra la mujer basada en el género". Universidad de Cartagena, 2010

la mujer suele experimentar sentimientos de angustia, ansiedad, miedo y desilusión, que desembocan en la segunda etapa que es la explosión, en la que suele experimentar miedo, odio, impotencia, soledad y dolor. Esta etapa será seguida por otra conocida como distanciamiento, en la que experimenta sentimientos de culpa, vergüenza, confusión, miedo, lástima propia y dolor, los cuales facilitan que ella misma se estimule a "renegociar" los términos de la relación y buscar una reconciliación y que esté propensa a ceder frente a una búsqueda y propuesta de reconciliación de parte del maltratador, cualquiera sea la intensidad del maltrato acontecido (p. 151-170) Así, en medio de sentimientos de miedo, confusión, ilusión, lástima y culpa, se reintenta recomponer aquella relación, que como carece de sincero arrepentimiento de parte del maltratador $y$, seguramente, de un proceso de terapia que le permita apropiarse del manejo de su conducta violenta, se posibilitarán de nuevo las situaciones de maltrato que motivan la acumulación de tensión original con la cual se inició el ciclo de violencia.

Tenemos entonces que la mujer maltratada resulta estar tan enferma que no es que "desea ser golpeada o humillada", y por ello no se separa de su maltratador, sino que:

- Las mujeres víctimas de la violencia sufren una desvalorización constante, que les impide utilizar sus escasos recursos emocionales.

- Otro problema añadido es el económico, porque a menudo no manejan dinero, aun cuando ellas trabajen y ganen su propio salario. 
- Sus posibilidades para elegir una salida las llevan a una elección perversa: la miseria absoluta o el maltrato por parte de su pareja.

- Así surge el autoengaño de creer que, en el fondo, su pareja la quiere y que es violento sólo porque tiene problemas.

- Ellas quieren creer que su pareja cambiará después de la agresión, pues posteriormente a ésta suele haber una etapa de arrepentimiento (ciclo TensiónAgresión-Arrepentimiento).

- Su inconsciente la llevará a pensar que, además, si tiene hijos, sufrirán afectiva y económicamente si se separa.

- A menudo la mujer tiene vergüenza de hacer pública su situación de maltrato frente a familiares y entorno en general.

- También tiene miedo a que su pareja la mate si se separa, miedo real en muchos casos tal como se está constatando cada día.

- Por todas estas razones busca, inconscientemente, más argumentos para no separarse y procura, además, no hacer cosas que crea que provocan al agresor: así la situación se autoalimenta.

- Por todas estas razones no se separan, o les cuesta mucho dar ese paso, de su maltratador. ${ }^{13}$

Walker (2010) fundamenta la superación de esa "impotencia aprendida" y condición de dependencia emocional de la mujer violentada, de esta manera:

Este punto de vista asume también que existen destrezas apropiadas que pueden aprenderse para poner fin al maltrato sin tener que dar por terminada la relación. De hecho, los datos obtenidos en el estudio respaldan la teoría de que lo único efectivo que pueden hacer las mujeres es marcharse, llegando incluso a verse obligadas a abandonar la ciudad y esconderse de su pareja para ponerse a salvo. Posteriormente se descubrió que, incluso marchándose, no se consigue impedir que la mujer sufra más abusos, ya que muchos hombres utilizan el régimen jurídico para continuar abusando de las mujeres denunciándolas en los tribunales y ejerciendo el control sobre sus finanzas y sus hijos (p. 41).

Aunque, sin negar las dificultades para ello, encontramos que esa condición de "impotencia aprendida" sí es posible de transformar y que una mujer violentada puedo lograr romper el ciclo de la violencia, superar el síndrome de mujer maltratada y desarrollar una psicología positiva que le permita alcanzar niveles de restauración para ella y para su familia.

\section{CORRESPONSABILIDAD ENTRE FAMILIA, SOCIEDAD Y ESTADO, PARA PREVENIR LA VIOLENCIA CONTRA LA MUJER}

La Ley 1257 de 2008 no deja toda la responsabilidad del tema de prevención de la violencia, al Estado, sino que de manera armoniosa, establece la corresponsabilidad

\footnotetext{
${ }^{13}$ Adaptado de CCM. (s.f) Violencia sobre las mujeres: algunas ideas falsas. Recuperado de: http://salud.ccm.net/faq/6047-violenciasobre-las-mujeres-algunas-ideas-falsas
} 
entre la familia, la sociedad y el Estado mismo. Por ello (y aunque quizás no deberían ni preveerse legalmente, porque son deberes surgidos del derecho natural) se estableció que en Colombia el núcleo familiar debe promover los derechos de las mujeres en todas sus etapas vitales y también promover la eliminación de todas las formas de violencia y desigualdad contra la mujer.

Y para lograr lo anterior, conforme al artículo 14 de la Ley 1257 de 2008, la familia debe:

* Abstenerse de realizar todo acto o conducta que implique maltrato físico, sexual, psicológico o patrimonial contra las mujeres, o que implique discriminación contra ellas; entendiéndose que las mujeres hagan parte de esa familia o no.

* Participar en los espacios democráticos de discusión, diseño, formulación y ejecución de políticas, planes, programas y proyectos de interés para la eliminación de la discriminación y la violencia contra las mujeres.

* Promover en el entorno familiar, la participación y el respeto de las mujeres en la toma de decisiones familiares.

* Respetar y promover el ejercicio de la autonomía de las mujeres, el ejercicio de sus derechos sexuales y reproductivos y Respetar sus manifestaciones culturales, religiosas, políticas y sexuales.

* Proporcionarle a las mujeres discapacitadas un trato digno e igualitario con todos los miembros de la familia y generar condiciones de equidad, de oportunidades y autonomía para que puedan ejercer sus derechos. Habilitar espacios adecuados y garantizarles su participación en los asuntos relacionados con su entorno familiar y social (art. 14).

$\mathrm{Y}$, atendiendo al reconocimiento constitucional de los pueblos indígenas, comunidades afrodescendientes y los demás grupos étnicos, la Ley prevé que las obligaciones de la familia en dichos grupos se establecerán de acuerdo con sus tradiciones y culturas, siempre que no sean contrarias a la Constitución Política y a los instrumentos internacionales de Derechos Humanos.

Las organizaciones de la sociedad civil, las asociaciones, las empresas, el comercio organizado, los gremios económicos y demás personas jurídicas y naturales que se describen como sociedad colombiana, conforme al artículo 15 de la Ley 1257 de 2008, deberán:

* Conocer, respetar y promover los derechos de las mujeres reconocidos señalados en esta ley.

* Abstenerse de realizar todo acto o conducta que implique maltrato físico, sexual, psicológico o patrimonial contra las mujeres, o discriminación en su contra.

* Denunciar las violaciones de los derechos de las mujeres y la violencia y discriminación en su contra y colaborar con las autoridades, en la ejecución de las políticas que promuevan los derechos de las mujeres y la eliminación de la violencia y la discriminación contra ellas.

* Participar activamente en la formulación, gestión, cumplimiento, evaluación y control de las políticas públicas relacionadas con los derechos de las mujeres y la eliminación de la violencia y la discriminación en su contra. 
Para la mayor comprensión de estas responsabilidades a cargo de la sociedad recomendamos la lectura de la sentencia T-878 de 2014, mediante la cual se ordenó a un empleador, persona jurídica de derecho privado, el reintegro de una mujer violentada, para protegerle su estabilidad económica, como respaldo para su recuperación de la violencia de género que le había sido infligida.

\section{CONCLUSIONES}

Hemos titulado este artículo No violencias contra la mujer. Derecho humano de carácter absoluto porque entendemos que toda mujer tiene derecho a una vida libre de violencias, tanto en el ámbito público como en el privado, como expresión del derecho fundamental de la dignidad. Ha sido el objetivo de este artículo presentar algunos conocimientos tanto científicos como legales que permitan reflexionar sobre otras formas de relaciones más amables, respetuosas y amorosas desde los hombres hacia las mujeres, mediante la propuesta de algunas acciones preventivas dirigidas a la eliminación de los estereotipos y roles de género.

La violencia contra la mujer, sólo por el hecho de ser mujer, denominada violencia basada en género contra la mujer, es una violencia justificada en la sumisión al hombre que se cree, debe tener la mujer, cualquiera que sea su condición frente a él. En la actualidad, para contrarrestar las consecuencias de esa violencia, es necesario y oportuno hacer uso, con el amparo de la Ley 1257 de 2008, de las llamadas acciones afirmativas o de "discriminación positiva", de tal manera que en espacios concretos se logre la finalidad de alcanzar una igualdad real entre hombres y mujeres, en la búsqueda del establecimiento de relaciones pacíficas, solidarias, respetuosas e igualitarias con las mujeres y la prevención y disminución de las agresiones contra ellas, por el hecho de ser mujeres, sin tener en cuenta condiciones de edad, sociales o de elecciones sexuales.

Una de las acciones que permite el éxito de esas medidas de discriminación positiva consiste en desarraigar del colectivo social particular en que nos desenvolvemos los diferentes mitos y prejuicios que perpetúan la violencia basada en el género contra la mujer, tales como el creer que: la violencia contra la mujer es un problema privado, la violencia contra las mujeres es un problema únicamente de las clases sociales más bajas, que la mujer habrá hecho algo para provocar la violencia en su hombre, o que las mujeres maltratadas no se separan porque les gusta que les peguen. De todos los mitos y prejuicios sobre la violencia contra la mujer, quizás es ese último, la falsa creencia de que la mujer no se separa porque le gusta que le peguen, el que más permite entender por qué la violencia ha sido normalizada y naturalizada por la propia cultura, hasta volverla invisible. Esta creencia también ha permitido desconocer (sin justificar que el hombre debe ser responsable por su propio comportamiento violento), que también existe un estado emocional y mental, conocido como el ciclo de la violencia, al que llega la mujer violentada. Éste consiste en una serie de emociones y sentimientos, originados en una 
impotencia aprendida, que le impiden tomar decisiones asertivas, para apartarse del agresor.

Para que una mujer pueda salir de este ciclo de violencia es importante que tanto la sociedad como la familia asuman la responsabilidad que tienen y contribuyan con el Estado en abstenerse de realizar todo acto o conducta que implique maltrato físico, sexual, psicológico o patrimonial contra las mujeres, o discriminación en su contra. Debe existir un compromiso en denunciar las violaciones de los derechos de las mujeres, la violencia y discriminación en su contra, facilitando las oportunidades que le protejan su estabilidad económica, como respaldo para su recuperación de la violencia de género que le había sido infligida. Esta situación resulta además estimulada por los beneficios que garantizan los decretos reglamentarios de la Ley 1257 de 2008 para quienes colaboran para la recuperación de una mujer violentada por razones de género.

\section{REFERENCIAS BIBLIOGRÁFICAS}

Bonder, G. (2010). Diplomado para la calidad de la atención a la violencia contra la mujer basada en el género. Universidad de Cartagena.

CCM. (s.f) Violencia sobre las mujeres: algunas ideas falsas. Recuperado de: http://salud. ccm.net/faq/6047-violencia-sobre-las-mujeres-algunas-ideas-falsas

Congreso de Colombia. (4 de diciembre del 2008). Normas de sensibilización, prevención y sanción de formas de violencia y discriminación contra las mujeres. [Ley 1257 de 2008].

Corte Constitucional, Sala Plena. (29 de septiembre del 2010). Sentencia C-776/10. [MP Jorge Iván Palacio Palacio].

. Sala Plena. (13 de junio del 2013). Sentencia C-335/13. [MP Jorge Ignacio Pretel Chaljub].

. Sala Quinta de Revisión. (18 de noviembre del 2014). Sentencia T-878 de 2014. [MP Jorge Iván Palacio Palacio].

. Sala Sexta de Revisión. (15 de diciembre del 2014). Sentencia T-967 de 2014. [MP Gloria Stella Ortiz Delgado].

Declaración sobre la eliminación de la violencia contra la mujer, proclamada por la Asamblea General de las Naciones Unidas en su Resolución 48/104, de 20 de diciembre de 1993. 
El Tiempo. (2014). Cada hora dos niños o niñas son víctimas de abuso sexual en Colombia. Recuperado de: http://www.eltiempo.com/archivo/documento/CMS-14850195

Naizara Rodriguez, H. (2008). Violencia de género en Cartagena de Indias: Crónicas e imágenes de un amor que se revela. Tratos inhumanos y crueles. PALOBRA, palabra que habla. Revista de la Facultad de Ciencias Sociales y Educación de la Universidad de Cartagena (185-199).

Programa de las Naciones Unidas para el Desarrollo PNUD. (2000). Objetivos del desarrollo del milenio. Recuperado de: http://www.co.undp.org/content/dam/colombia/ docs/ODM/undp-co-odsinformedoc-2015.pdf

Programa de las Naciones Unidas para el Desarrollo en Colombia. (s.f.) Promover la igualdad entre los géneros y la autonomía de la mujer. Recuperado de: http://www. co.undp.org/content/colombia/es/home/post-2015/mdgoverview/overview/ mdg3.html

Ruiz, Y. La violencia contra la mujer en la sociedad actual: análisis y propuestas de prevención. Jornades de Foment de la Investigacion. Recuperado de: http:// repositori.uji.es/xmlui/bitstream/handle/10234/78453/forum_2007_18. pdf?sequence $=1$

Sierra, Z. Otra herencia colonial, el carácter androcéntrico y sexista del conocimiento. Mujer, Revista Javeriana, 2007 (p.60-69).

Walker, L. (2012). El síndrome de la mujer maltratada. España: Editorial Desclée De Brouwer. 